\title{
Faculty Mentoring: Shaping A Program
}

Judson Faurer, Metropolitan State University of Denver, USA

Cynthia Sutton, Metropolitan State University of Denver, USA

Larry Worster, Metropolitan State University of Denver, USA

\begin{abstract}
A well developed mentoring program should not be just considered another faculty activity but rather a significant program that can define a preeminent academic institution. A Faculty Learning Community (FLC) at Metropolitan State University of Denver (MSU Denver) was charged with determining whether the needs of new faculty members and the institution were being addressed in a manner that would optimize the productivity, acclimation, and professional enhancement of those new faculty members who would eventually be the foundation of the institution's future. The FLC conducted a year-long study and an extensive survey in order to provide the administration with findings, suggestions, and recommendations for shaping a faculty mentoring program for the future.
\end{abstract}

Keywords: Faculty Mentoring; Faculty Learning Community

\section{INTRODUCTION}

"Would you tell me, please, which way I ought to go from here?"

"That depends a good deal on where you want to get to," said the Cat.

"I don't much care where---" said Alice.

"Then it doesn't matter which way you go," said the Cat.

"---So long as I get somewhere," Alice added as an explanation.

"Oh you're sure to do that," said the Cat, "if you only walk long enough."

Alice's Adventures in Wonderland by Lewis Carroll

\section{BACKGROUND}

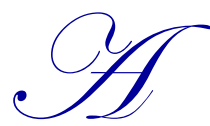

s the above quote reasons, the path a newly hired faculty member takes will go somewhere, but the road to success poses varied obstacles to tenure, promotion, and retention. Whether just entering academic teaching or an experienced instructor, a new faculty member faces a daunting environment. As the preamble to the past television hit "Cheers" so aptly states, "Making your way in the world today takes everything you got." Helping the new faculty member travel the right road in achieving the desired goals (stated above) is largely the optimum intent of a well developed mentoring program.

Within the past year, the Center for Faculty Development at a state university (MSU Denver) assumed the task of critically reviewing the university's existing early career faculty member development program. The charge was to determine whether the needs of both new faculty members and the university were being addressed in a manner that would optimize the productivity, acclimation, and professional enhancement of those faculty members who would eventually be the foundation of the university's future in transitioning from an urban college to a preeminent university.

The Center for Faculty Development formed a Faculty Learning Community (FLC) consisting of a cross section of both tenured and non-tenured faculty members committed to a year-long schedule of meetings. The FLC researched published materials regarding mentoring and reviewed, discussed, and assimilated findings. The FLC developed an extensive survey that was administered to the entire faculty. It was obvious from the initial meeting of the FLC participants that perspectives as to the meaning, intent, and administration of a mentoring program were varied due to individual past experiences in either the non-academic or academic workplace. Nevertheless, the FLC 
acknowledged that the first few years in a professor's career (including the job search) are enormously critical. During this time, applicants and new hires most need useful advice but are least likely to receive it. Often, any proffered advice (from different sources) is so conflicting and confusing that new professors may be tempted to ignore all of it (Boice, 2002).

Johnson (2006) suggests that the difference in rank and tenure among faculty members involved in a mentoring relationship can mount barriers for the "safe" or natural exchange of information between mentor and mentee. The FLC further acknowledged that guidebooks such as Advice for New Faculty Members can offer sage advice on topics such as teaching, writing productively, and socialization. However, finding the time to digest such lengthy tomes invariably takes a back seat to more urgent tasks when faced with limited days for required course preparation. Mentoring becomes even more valuable during challenging times because it offers many benefits for negligible costs (Hodgkin, 2010).

The task undertaken by the FLC to study the existing mentorship program turned out to be a formidable one and far more involved than expected. Through the years significant time and money had been expended in developing and implementing the mentoring program at the university. However, good intentions do not necessarily result in meaningful or successful outcomes. Zachary (2000) noted that successful mentoring programs are sustained over time when they are embedded in organizational cultures that value continuous learning. The FLC recognized early on that developing such a program had as its goal the seamless integration of the new faculty member toward productive teaching, career progress, and as a contributing department member. Weimer (2002) also proffers that faculty development has taught some important lessons, one of the clearest being that efforts to improve instruction cannot be based on premises of remediation and deficiency.

The results of the survey provided significant insights into faculty member perspectives on mentoring beyond the FLC's expectations with implications applicable to any educational institution interested in optimizing the benefits of a mentoring program. This paper presents the cogent aspects of the faculty survey along with the accompanying descriptive statistical data. It is reasonable to assume that the faculty at the university is representative of most university faculties with regard to faculty demographics, availability of various academic disciplines, and organizational structure. Therefore, conclusions may be of value to any institution seeking to review or re-evaluate an existing mentoring program.

\section{THE DATA}

Synopsizing the survey results found in the appendices (available from the authors upon request), the first item of interest is that the voluntary response to the survey administered via email to the entire full time faculty resulted in a 52\% response (175 participants), the majority of which were non-tenured with less than five-years of service. About half of the participants had been at the university before being hired in tenure track positions. This percentage signifies that faculty members were interested in the topic and felt their responses could make a difference in analyzing the mentoring program. Other results deemed significant are highlighted as follows:

- Mentors paid more than cursory attention to this commitment to their mentees with frequent meetings. The amount of actual time spent with the mentee was not explored.

- $\quad$ Many mentees and mentors (44.1\% and 47.2\%, respectively) will continue relationships after completion of the year long mentoring program. This bodes well not only for the development of faculty solidarity, but the long term benefits at collaboration with experienced faculty.

- In response to the stated learning objectives of a mentoring program, mentors reacted ambivalently as to whether the program fostered a meaningful relationship between mentor and mentee, enhanced success as a teacher, or contributed to the art of congeniality.

- $\quad$ The conduct and administration of past mentoring programs was such that both mentors and mentees indicated less than optimum desired outcome. This could be attributed to the selection and orientation of mentors.

- $\quad$ Overall perception of the current program was that it is viable in meeting the intended purpose but less than exemplary. 
- The preparation of chosen mentors was acceptable, but seems to reflect disparity between what should be done versus what could be mandated by administration.

- $\quad$ Mentees (being on the receiving end of the program's benefits) perceive that preparation of mentors, while acceptable, could be enhanced through mentor development activities.

- Mentors were in strong agreement across all questions regarding their training that the need exists for mentor training or (at least) re-exposure to dossier preparation, existing academic policies, desired teaching skills, and interpersonal skills.

- $\quad$ The key to selection of mentors should focus on knowledge of institution resources and environment as well as interpersonal as opposed to length of experience and academic rank.

- $\quad$ The view that chosen mentors should be paired with mentees with whom they share similar professional development goals may be desirable. However, this poses a problem of knowing a mentee's goals at the time of the pairings without some form of consultation between prospective mentors and mentees.

- $\quad$ Both mentors and mentees lean slightly toward a one year formal mentoring program, but there is support for one longer than a year.

- $\quad$ Starting the mentor program before the first semester contract would primarily accommodate the training of selected mentors before pairing with mentees, but would involve a compensation issue outside normal terms of faculty member contracts. For mentees, any mentoring information could be accomplished during new faculty member orientation and compensated accordingly.

- Interestingly, mentors were more concerned with recognition in their dossiers than other incentives to volunteer to make up for the time devoted to mentees versus involvement in other dossier documented activities; i.e. service to the university. Mentees, on the other hand, viewed recognition in the dossier as an important addition for their mentors.

- $\quad$ Even though mentees may be required to engage in the mentoring program, they also recognized the value of "fodder" for their dossier.

- While the underlying reasons for wanting to be involved as a mentor will undoubtedly vary, the response from those taking the survey support the need for and benefits to all of a well developed mentor program.

- In addition to the responses to the 22 questions posed in the basic faculty survey, comments were solicited from all respondents resulting in 28 single spaced typed pages of suggestions, observations, opinions (both positive and negative), and general thoughts about both the existing mentoring program and mentoring programs in general.

- $\quad$ Selected quotes from the question "If you had one message to send to the Provost..." There were 86 responses to this inquiry clearly demonstrating the multitude of thoughts given to the question.

\section{CONCLUSIONS}

With the intent of the survey being to evaluate the existing mentoring program with a view toward shaping the program for the future, several formidable conclusions were drawn. It was acknowledged that mentoring faculty members is important for any academic institution of higher learning and that administration and length of a mentoring program should incorporate some pertinent baseline practices. For instance, first year faculty members should have development opportunities outside the mentoring program. Workshops should be offered during the week before the first contract date. Mentees also should be paired with mentors on the basis of professional development and teaching goals and engage in the program for more than one year. Additionally, first year faculty members should receive an honorarium for workshop days. Mentors should be chosen for their knowledge of the institution's resources and their interpersonal skills, should have development opportunities as mentors, and should be provided incentives to serve as a mentor such as inclusion in their promotion and tenure dossiers.

\section{RECOMMENDATIONS}

Recommendations were derived from the survey of all full time faculty members as to the future of early career faculty development at the University focused on the new faculty member's first two years. 


\section{First Year: Nuts and Bolts}

Selected mentors should be designated as first-year guides, should have access to necessary information on resources, meet regularly to receive training in university resources and (in goal setting for first-year faculty members), provide guidance in setting appropriate goals in all areas of development, and be knowledgeable of the retention, tenure, and promotion process. They should be chosen from those volunteering for the program and selected based on personal attributes of knowledge of institutional resources, interpersonal skills, and demonstrated excellence in all areas of faculty member evaluation. The pairing with appropriate mentees should consider their respective professional development goals and compatibility.

\section{Second Year: Professional and Personal Growth}

Developmental activities in the area of teaching and advising should be of sufficient variety and quantity that all early-career faculty members are able to participate. Mentors and mentees should have opportunities to engage in activities designed to enhance the interpersonal relationships. Mentors should be provided a stipend to offset cost of lunch or dinner meetings during the year.

\section{NOTE}

Survey result details are available from the corresponding author by emailing Jud Faurer at faurerj@ msudenver.edu.

\section{AUTHOR INFORMATION}

Jud Faurer has a PhD in Higher Education from University of Denver, MBA from Ohio State, and BS from the United States Military Academy. He has been a professor of Management at Metropolitan State University of Denver for 30 years teaching Organizational Management both online and on campus. His research efforts relate to the integration of his management background with pedagogical effectiveness from the both faculty and student perspectives. E-mail: faurerj@ msudenver.edu (Corresponding author)

Cindy Sutton, Ph.D., is a Professor of Management at Metropolitan State University of Denver. Her Ph.D. in Administrative Management (emphasis in Human Resource Management) is from Arizona State University. Her B.S. in Business Administration and M.S. in Management are from Colorado State University. Much of Dr. Sutton's research addresses job values, performance appraisals, generational differences of employees, learning styles, and writing cases on organizational practices. E-mail: suttoncy@ msudenver.edu

Larry Worster, Ph.D. Although he had initially studied chemistry as a young man, Dr. Larry Worster enrolled in CU-Boulder, initially studying classical guitar before turning to musicology for his graduate degrees. He has been on the faculty at MSU Denver since 1994 coordinating the music literature, history, and senior project classes as well as advising all string and guitar students. He feels a special respect for the student body at MSU Denver, having returned to college in his late $30 \mathrm{~s}$ and completed his music degrees while working and raising his family. E-mail: worster@msudenver.edu

\section{REFERENCES}

1. $\quad$ Boice, R. (2000). Advice for new faculty members. Needham Heights, Mass: Allyn \& Bacon.

2. Hodgkin, D. (2010, September 27). Mentoring can be a smart practice for your company. Denver Business Journal. Retrieved January 6, 2014 from http://www.bizjournals.com/denver/stories/2010/09/27/smallb1.html?page=all

3. Johnson, W. B. (2006). The contours of mentoring. On Being a Mentor: A Guide for Higher Education Faculty, New Jersey: Lawrence Eribaum Associates.

4. MacDonald, L. (2010). Why know what? What is important or pertinent for mentors and mentees to share. (Unpublished paper). Metropolitan State College of Denver.

5. Weimer, M. (2002). Learner centered teaching. San Francisco: Jossey-Bass.

6. Zachary, L. J. (2000). The mentor's guide. San Francisco: Jossey-Bass. 